\title{
A comparative study between all-electron scalar relativistic calculation and all-electron calculation on the adsorption of hydrogen molecule onto small gold clusters
}

\author{
XIANG-JUN KUANG ${ }^{\mathrm{a}, \mathrm{b}, *}$, XIN-QIANG WANG ${ }^{\mathrm{b}}$ and GAO-BIN LIU ${ }^{\mathrm{b}}$ \\ ${ }^{a}$ School of Science, Southwest University of Science and Technology, Mianyang, Sichuan, 621010, China \\ ${ }^{\mathrm{b}}$ College of Physics, Chongqing University, Chongqing, 400044, China \\ e-mail: kuangxiangjun@163.com
}

MS received 22 May 2012; revised 21 July 2012; accepted 2 August 2012

\begin{abstract}
A comparative study between all-electron relativistic (AER) calculation and all-electron (AE) calculation on the $\mathrm{H}_{2}$ molecule adsorption onto small gold clusters has been performed. Compared with the corresponding $\mathrm{Au}_{n} \mathrm{H}_{2}$ cluster obtained by AE method, the $\mathrm{Au}_{n} \mathrm{H}_{2}$ cluster obtained by AER method has much shorter $\mathrm{Au}-\mathrm{H}$ bond-length, much longer $\mathrm{H}-\mathrm{H}$ distance, larger binding energy and adsorption energy, higher vertical ionization potentials (VIP), greater charge transfer, higher vibrational frequency of Au-H mode and lower vibrational frequency of $\mathrm{H}-\mathrm{H}$ mode. The delocalization of the highest occupied molecular orbital (HOMO) and the lowest unoccupied molecular orbital (LUMO) for $\mathrm{Au}_{n} \mathrm{H}_{2}$ cluster obtained by AER method is obvious. All these characteristics suggest that the scalar relativistic effect might strengthen the $\mathrm{Au}-\mathrm{H}$ bond and weaken the $\mathrm{H}-\mathrm{H}$ bond. It is believed that the scalar relativistic effect is favourable to the $\mathrm{H}_{2}$ molecule adsorption onto small gold cluster and the reactivity enhancement of $\mathrm{H}_{2}$ molecule. It may be one of the reasons why the dissociative adsorptions take place in some $\mathrm{Au}_{n} \mathrm{H}_{2}$ clusters. With increasing size of $\mathrm{Au}_{n} \mathrm{H}_{2}$ clusters, the influence of scalar relativistic effect becomes more significant. Some further studies focused on the influence of scalar relativistic effect on the adsorption behaviour of other small molecules onto gold clusters are necessary in the future.
\end{abstract}

Keywords. Small gold cluster; hydrogen molecule; adsorption; scalar relativistic effect.

\section{Introduction}

Small gold clusters have attracted much attention from both industrial and scientific areas due to their unique physical and chemical properties strongly dependent on the cluster size. ${ }^{1-3}$ Although the bulk gold is one of the most chemically inert metals, gold clusters, the size of which is as small as $2-3 \mathrm{~nm}$, are efficient catalysts for various chemical reactions. ${ }^{4-7}$ Previous studies have reported that small gold catalysts could be applied to many oxidation and hydrogenation reactions at low temperatures. These reactions include $\mathrm{CO}$ and $\mathrm{NO}$ oxidations, ${ }^{8}$ partial oxidation of propylene, ${ }^{9}$ partial hydrogenation of acetylene, ${ }^{10}$ hydrogenations of ethylene, ${ }^{11}$ and so on. Even more interesting is the partial oxidation of propylene to propylene oxide, by a mixture of hydrogen and oxygen, which is catalysed by small gold clusters supported on TiO. ${ }^{12-16}$ The presence of hydrogen in the oxidation reaction is rather unusual and still not understood well. ${ }^{17}$ Consequently, some further study on

*For correspondence the role of hydrogen in this process may have practical applications.

Stimulating by this unusual phenomenon, the adsorption behaviour of hydrogen molecule onto small gold clusters has been studied experimentally and theoretically. ${ }^{17-24}$ Varganov et al. have studied the reaction of molecular hydrogen with the dimer and trimer gold clusters by using DFT, second order perturbation theory and coupled cluster methods. ${ }^{17}$ They report that $\mathrm{H}_{2}$ molecules can be easily bonded with neutral $\mathrm{Au}_{2}$ and $\mathrm{Au}_{3}$ clusters but can not form stable complexes with $\mathrm{Au}_{2}^{-}$and $\mathrm{Au}_{3}^{-}$clusters. Okumura et al. have carried out a hybrid density functional calculation on $\mathrm{Au}_{13} \mathrm{H}_{2}$ cluster to discuss the catalytic behaviour of $\mathrm{Au}$ cluster. ${ }^{18}$ It is suggested that the Au nanoparticle has a stable chemisorption state of $\mathrm{H}$ atom and has the ability to dissociate $\mathrm{H}_{2}$ at low temperature. Ghebriel et al. have presented a theoretical investigation on the adsorption of $\mathrm{H}_{2}$ and $\mathrm{H}_{2} \mathrm{~S}$ molecules onto small neutral and cationic gold clusters by using density functional theory with the generalized gradient approximation. ${ }^{19}$ It has been shown that $\mathrm{H}_{2}$ molecule weakly bonds to the neutral gold clusters as compared to the corresponding cationic clusters. The adsorbed molecules get attached to a 
single gold atom and there is no preference to get adsorbed at places between the gold atoms. In most cases, the geometry of the lowest energy gold cluster remains planar structure even after the adsorption. Kang et al. have investigated the adsorption and dissociation of $\mathrm{H}_{2}$ on the neutral and charged gold clusters by using the density functional theory Perdew-Wang 1991 (PW91) functional. ${ }^{20}$ They find that $\mathrm{H}_{2}$ interacts very weakly with $\mathrm{Au}_{n}^{-1}$, whereas the interaction with $\mathrm{Au}_{n}^{+1}$ is relatively strong. The $\mathrm{H}_{2}$ molecule dissociates facilely at low temperatures on both neutral and cationic $\mathrm{Au}_{4}$ and $\mathrm{Au}_{5}$ clusters.

Although there are some studies on the adsorption behaviour of hydrogen molecule onto small gold clusters, some questions concerning the $\mathrm{H}_{2}$ dissociation remain unclear. ${ }^{25-29}$ Corma et al. investigate the $\mathrm{H}_{2}$ dissociation on gold by using three different models. ${ }^{25}$ They find that on four-coordinated $\mathrm{Au}$ atoms, $\mathrm{H}_{2}$ dissociation is facile while on five-coordinated $\mathrm{Au}$ atoms or surfaces, the dissociation is difficult. They conclude that the existence of low coordinated $\mathrm{Au}$ atoms would be the sufficient and necessary condition for $\mathrm{H}_{2}$ dissociation. However, Strømsnes et al. report a quite high dissociation barrier of $1.95 \mathrm{eV}$ on a four-coordinated $\mathrm{Au}$ atom. ${ }^{26}$ Hence the relationship between the coordination number of the Au atom and the feasibility of $\mathrm{H}_{2}$ dissociation is still inconclusive. Recently, Kan et al. indicate that the reason of $\mathrm{H}_{2}$ dissociation is not the higher dissociation barrier and weak bond of $\mathrm{H}_{2} .{ }^{20}$ The coordination number of the Au atom may not play a determining role in $\mathrm{H}_{2}$ dissociation. For the first time, they suggest that $\mathrm{H}_{2}$ dissociation may involve the valleyridge inflection points on some clusters. Besides the questions of dissociative adsorption toward $\mathrm{H}_{2}$, another important research point is the influence of scalar relativistic effect on the adsorption behaviour of small gold clusters. Gold being a heavy element, the scalar relativistic effect of outer shell electrons is obvious and can not be neglected. ${ }^{30-34}$ Furthermore, previous studies. ${ }^{35,36}$ indicate that the reason for the preference of planar structures by gold clusters up to large size may be attributed to the scalar relativistic effects that cause a shrinking of the size of the $s$ orbitals and thus enhance the $s-d$ hybridization. This phenomenon also can be observed in other coinage metal clusters, such as Ag, $\mathrm{Cu}$, and is most strikingly evident in gold cluster and called 'gold maximum'. ${ }^{37}$ So for coinage metal cluster in general, and gold cluster in particular, it is essential to study the scalar relativistic effect on the adsorption behaviour. In this paper, we perform a comparative study between all-electron scalar relativistic (AER) calculation and all-electron (AE) calculation on the hydrogen molecule adsorption onto small gold clusters $(n=$
1 - 13) by using density functional theory with the generalized gradient approximation at PW91 level and try to answer the question whether and how the scalar relativistic effect will affect the adsorption behaviour of small gold clusters toward hydrogen molecule. We hope that our study can help people understand the interaction between small gold clusters and hydrogen molecule better. The paper is arranged as follows: the computational method and cluster model are described in section 2, calculation results and discussions are presented in section 3 and the main conclusions are summarized in section 4 .

\section{Computational method and cluster model}

All calculations are based on spin-polarized density functional theory (DFT) in the DMOL 3 program package. ${ }^{38,39}$ A high quality double-numerical with polarization (DNP) basis set is chosen to describe the electronic wave functions. Within the generalized gradient approximation (GGA), the Perdew-Wang 91 exchangecorrelation (XC) functional (PW91), ${ }^{40}$ combined with the DFT-basis all-electron treatment and all-electron relativistic four-component Dirac-Kohn-Sham procedure for clusters containing heavy elements is adopted in the calculations. ${ }^{41,42}$ These potentials do not replace core electrons; instead they supplement the core potentials with approximate relativistic effects. Such effects are important for heavier elements, and are certainly required starting with the second row of transition metals. Using these potentials may yield the most accurate results, though at the highest cost. ${ }^{38-42}$

The self-consistent field (SCF) tolerance is set to be $1.0 \times 10^{-6} \mathrm{eV}$. In order to accelerate the calculation, the direct inversion in iterative subspace (DIIS) approach is used and the smearing value is set to be $0.005 \mathrm{Ha}$. During the structure optimization, the spin is unrestricted and the symmetry of the structure has no constraint. The convergence tolerance of max force, max energy and max displacement is $0.002 \mathrm{Ha} / \AA$, $1.0 \times 10^{-5} \mathrm{Ha}$ and $0.005 \AA$, respectively. During the structure relaxation, the spin multiplicity will be considered at least 2, 4 and 6 for odd-electrons $\mathrm{Au}_{n} \mathrm{H}_{2}$ clusters $(n=1,3,5$, 7, 9, 11 and 13) and 1, 3, 5 for even-electrons $\mathrm{Au}_{n} \mathrm{H}_{2}$ clusters ( $n=2,4,6,8,10$ and 12). If the total energy decreases with the increasing of spin multiplicity, the high spin state will be considered until the energy minimum with respect to the spin multiplicity is reached. In addition, the stability of the optimized geometry is confirmed without any imaginary frequency by computing vibrational frequencies at the same level of theory. 
The choice of distinct initial geometries is important to the reliability of obtained lowest energy structures. In this work, we get the initial structures by the following way: First, considering previous studies on the configurations of pure gold clusters, ${ }^{43-45}$ we optimize the structures of pure $\mathrm{Au}_{n}$ clusters and free $\mathrm{H}_{2}$ molecule by using the AER method and AE method, respectively. Based on the optimized equilibrium geometries of pure gold clusters and free $\mathrm{H}_{2}$ molecule, we obtain the initial structures of $\mathrm{Au}_{n} \mathrm{H}_{2}$ clusters by adding $\mathrm{H}_{2}$ molecule directly on each possible non-equivalent site of $\mathrm{Au}_{n}$ cluster including all possible bonding patterns. All these initial structures are fully optimized by relaxing the atomic positions until the force acting on each atom vanishes (typically $\left|F_{i}\right| \leq 0.002 \mathrm{Ha} / \AA \AA \mathrm{A}$ ) and by minimizing the total energy by using the AER and AE method, respectively.

In order to check the intrinsic reliability of various functional forms, we chose $\mathrm{Au}_{2}, \mathrm{Au}_{3}$ and $\mathrm{AuH}$ as examples to calculate some properties (the corresponding experimental data are available for these clusters) by using the GGA-PW91, GGA-(BeckePerdew) BP, GGA-(Perdew, Burke and Enzerhof) PBE, GGA- (Becke-Lee-Yang-Parr) BLYP and (Local Density Approximation-Perdew-Wang 1992) LDA-PWC, LDA-(Vosko-Wilk-Nusair) VWN functional forms, respectively. From the AER calculation, the results listed in table 1, we can see that the results obtained by using the GGA-PW91 functional form are more close to the available experimental data. ${ }^{43-48}$ This indicates that among all these available functional forms, the GGAPW91 functional is the most reliable and accurate one for the study of pure $\mathrm{Au}_{n}$ clusters and $\mathrm{Au}_{n} \mathrm{H}_{2}$ clusters. Although there is possibly no available experimental data for comparison between experimental and theoretical results, some previous research reports ${ }^{44,49-52}$ used similar techniques demonstrate that the AER and AE method adopted in this paper are recognizable.

\section{Results and discussion}

\subsection{Geometrical structures}

In order to acquire the initial structures of $\mathrm{Au}_{n} \mathrm{H}_{2}$ clusters, we optimize the pure $\mathrm{Au}_{n}$ clusters and single $\mathrm{H}_{2}$ molecule by using AER and AE method, respectively. The optimized geometries of $\mathrm{Au}_{n}$ clusters and single $\mathrm{H}_{2}$ molecule are shown in figure 1 . For single $\mathrm{H}_{2}$ molecule, the $\mathrm{H}-\mathrm{H}$ bond-lengths of AER calculation and AE calculation, which are adopted to compare with those of $\mathrm{H}_{2}$ after adsorption, are the same value of $0.728 \AA$ and in good agreement with the experimental value of $0.7414 \AA .{ }^{53}$ This situation indicates that the scalar relativistic effect almost has no influence on single $\mathrm{H}_{2}$ molecule. For pure $\mathrm{Au}_{n}$ clusters, the planar structures obtained by AER method are in good agreement with previous works. ${ }^{43-45} \mathrm{But}$, the average $\mathrm{Au}-\mathrm{Au}$ bondlength of planar structure obtained by $\mathrm{AE}$ method is much longer than that of corresponding planar structures obtained by AER method. This indicates that the scalar relativistic effect may enhance the $\mathrm{Au}-\mathrm{Au}$ bond significantly. Then, based on the optimized lowest energy structures of $\mathrm{Au}_{n}$ clusters, we perform an extensive lowest energy structure search for $\mathrm{H}_{2}$ molecule adsorption onto small gold cluster according to the way described in section 2. The lowest energy structures of $\mathrm{Au}_{n} \mathrm{H}_{2}(n=1-13)$ clusters obtained by AER and AE method are displayed in figure 1 comparatively. For the lowest energy geometries of $\mathrm{Au}_{n} \mathrm{H}_{2}(n=1-13)$ clusters obtained by $\mathrm{AE}$ method, the $\mathrm{H}-\mathrm{H}$ bond-lengths are slightly longer than that of single $\mathrm{H}_{2}$ molecule. The $\mathrm{H}_{2}$ structures in these $\mathrm{Au}_{n} \mathrm{H}_{2}$ clusters are slightly perturbed and still keep the structure like single $\mathrm{H}_{2}$ molecule. This picture indicates that only molecular adsorptions take place in these $\mathrm{Au}_{n} \mathrm{H}_{2}$ clusters without including scalar relativistic effect. For the lowest energy geometries of $\mathrm{Au}_{n} \mathrm{H}_{2}(n=1-13)$ clusters obtained by AER

Table 1. AER calculation results comparison between different functional forms for some properties of $\mathrm{Au}_{2}, \mathrm{Au}_{3}$ and $\mathrm{AuH}_{\mathrm{H}}$ clusters.

\begin{tabular}{|c|c|c|c|c|c|c|c|}
\hline \multirow{2}{*}{$\begin{array}{l}\text { Cluster } \\
\text { Properties }\end{array}$} & \multicolumn{4}{|c|}{$\mathrm{Au}_{2}$} & \multirow{2}{*}{$\begin{array}{c}\mathrm{Au}_{3} \\
\mathrm{VIP}(\mathrm{eV})\end{array}$} & \multicolumn{2}{|c|}{$\mathrm{AuH}$} \\
\hline & $R(\AA)$ & $E_{b}(\mathrm{eV} /$ atom $)$ & $\mathrm{VIP}(\mathrm{eV})$ & $v\left(\mathrm{~cm}^{-1}\right)$ & & $R(\AA)$ & $E_{b}(\mathrm{eV} /$ atom $)$ \\
\hline GGA-PW91 & 2.487 & 1.221 & 9.381 & 183.1 & 7.443 & 1.521 & 1.671 \\
\hline GGA-BP & 2.489 & 1.138 & 9.372 & 181.5 & 7.375 & 1.514 & 1.653 \\
\hline GGA-PBE & 2.488 & 1.189 & 9.376 & 181.7 & 7.369 & 1.516 & 1.652 \\
\hline GGA-BLYP & 2.528 & 1.104 & 9.192 & 169.8 & 7.285 & 1.519 & 1.646 \\
\hline LDA-PWC & 2.437 & 1.505 & 9.611 & 201.2 & 7.694 & 1.502 & 1.923 \\
\hline LDA-VWN & 2.436 & 1.502 & 9.613 & 200.9 & 7.699 & 1.501 & 1.926 \\
\hline $\operatorname{Exp}$ & 2.470 & 1.225 & 9.400 & 191.0 & 7.500 & 1.524 & 1.680 \\
\hline
\end{tabular}



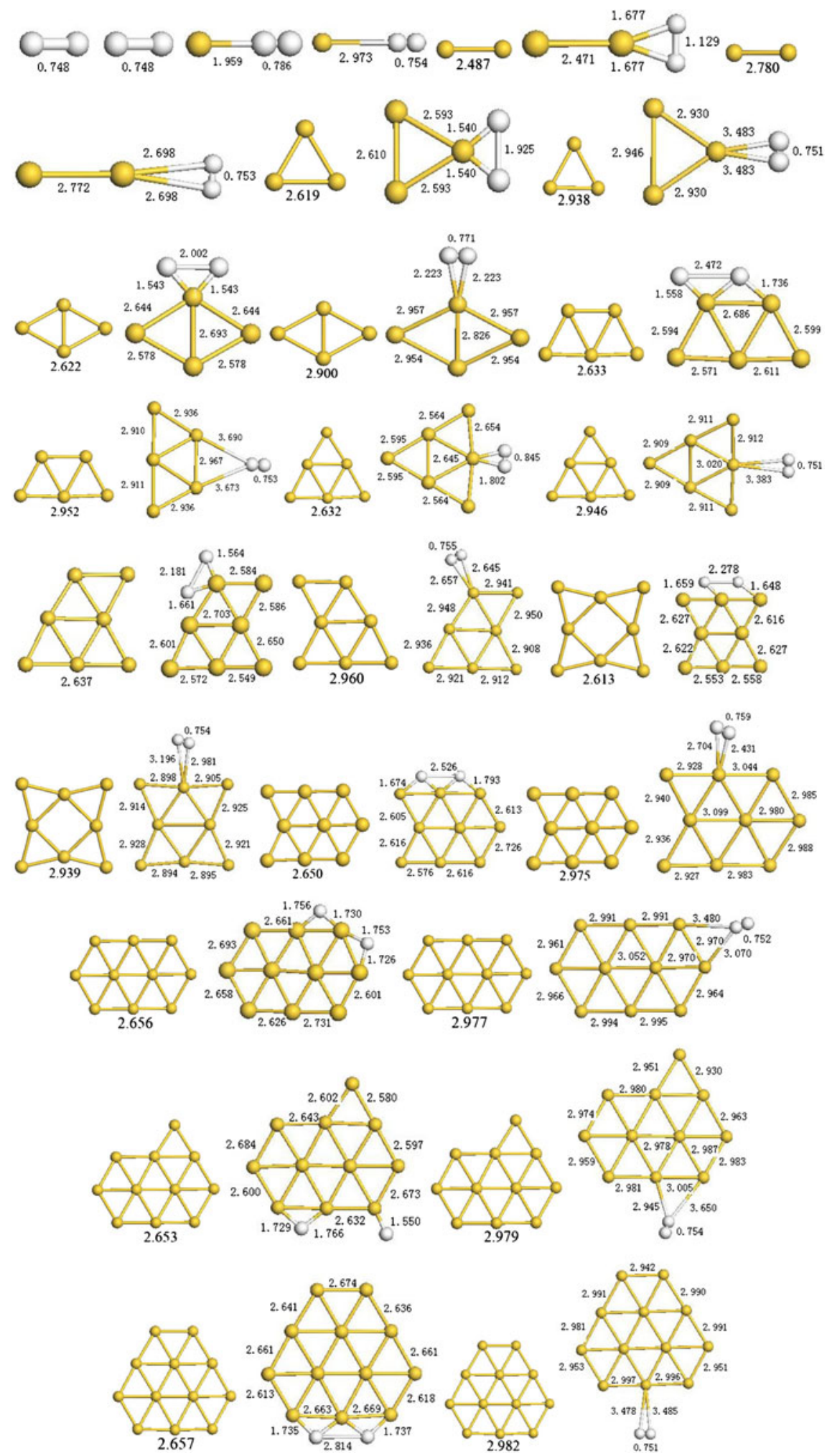

Figure 1. Lowest energy geometries for pure $\mathrm{Au}_{n}$ clusters and $\mathrm{Au}_{n} \mathrm{H}_{2}(n=$ 1-13) clusters. Every cluster has two figures, fisrt one for AER calculation and second one for AE calculation.

method, the lengthening of $\mathrm{H}-\mathrm{H}$ distance is very obvious and significant. The $\mathrm{H}-\mathrm{H}$ distance in $\mathrm{Au}_{n} \mathrm{H}_{2}$ cluster obtained by AER is much longer than that of corresponding $\mathrm{Au}_{n} \mathrm{H}_{2}$ cluster obtained by $\mathrm{AE}$. For $\mathrm{AuH}_{2}$,
$\mathrm{Au}_{2} \mathrm{H}_{2}$ and $\mathrm{Au}_{6} \mathrm{H}_{2}$ clusters, the $\mathrm{H}-\mathrm{H}$ distances are the values of $0.786 \AA, 1.129 \AA$ and $0.845 \AA$, respectively. The $\mathrm{H}_{2}$ still can be regarded as molecule and molecular adsorptions take place in these clusters. But, in other 

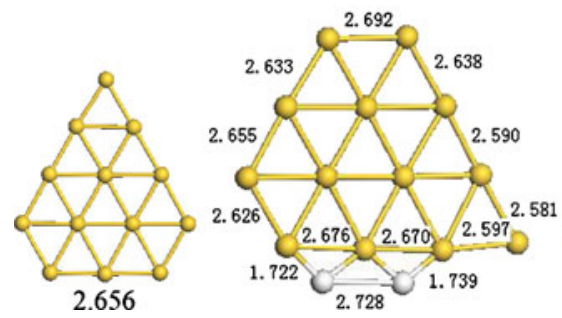

Figure
$\mathrm{Au}_{n} \mathrm{H}_{2}$ clusters, the $\mathrm{H}-\mathrm{H}$ distances are elongated from $0.748 \AA$ to the value of more than $2.000 \AA$. The $\mathrm{H}_{2}$ is obviously dissociated and dissociative adsorptions take place in these $\mathrm{Au}_{n} \mathrm{H}_{2}$ clusters definitely. All these dissociative adsorptions are found to be favourable to two, three and four-coordinated $\mathrm{Au}$ atoms, no dissociative adsorption on five and six-coordinated Au atoms can be found. The low-coordinated $\mathrm{Au}$ atoms are more reactive toward $\mathrm{H}_{2}$ molecule than the high-coordinated $\mathrm{Au}$ atoms. This situation is consistent well with previous work $^{25}$ and may be understood in terms of the lack of charge transfer channels and electron pairing chance for low-coordinated Au atoms. Meanwhile, we can also see that the $\mathrm{Au}-\mathrm{H}$ bond-length in $\mathrm{Au}_{n} \mathrm{H}_{2}$ cluster obtained by AER method is significantly shorter than that of corresponding $\mathrm{Au}_{n} \mathrm{H}_{2}$ cluster obtained by $\mathrm{AE}$ method, indicating that the strength of $\mathrm{Au}-\mathrm{H}$ bond in $\mathrm{Au}_{n} \mathrm{H}_{2}$ cluster obtained by AER method is greatly stronger than that of $\mathrm{Au}-\mathrm{H}$ bond in $\mathrm{Au}_{n} \mathrm{H}_{2}$ cluster obtained by $\mathrm{AE}$ method. For $\mathrm{Au}_{n} \mathrm{H}_{2}(n=1-8)$ clusters, the $\mathrm{Au}-\mathrm{H}$ bond-length and $\mathrm{H}-\mathrm{H}$ bond-length obtained by AER method in our work are shorter and longer than the corresponding bond-length in previous work ${ }^{19}$ (see figures 2 and 3), respectively. All these characteristics of geometrical structure demonstrate that the scalar relativistic

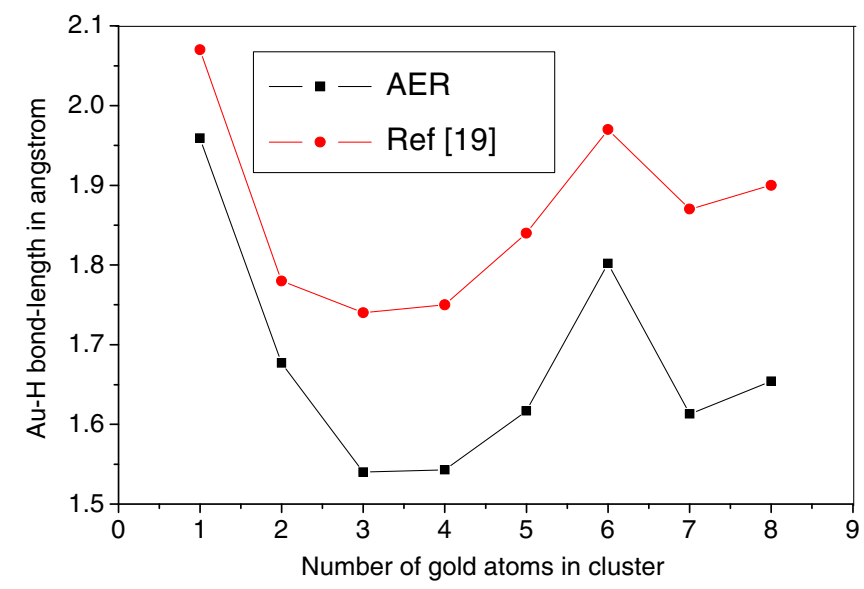

Figure 2. Au-H bond-length comparison between AER calculation and Ref.19 for $\mathrm{Au}_{n} \mathrm{H}_{2}(n=1-8)$ clusters.
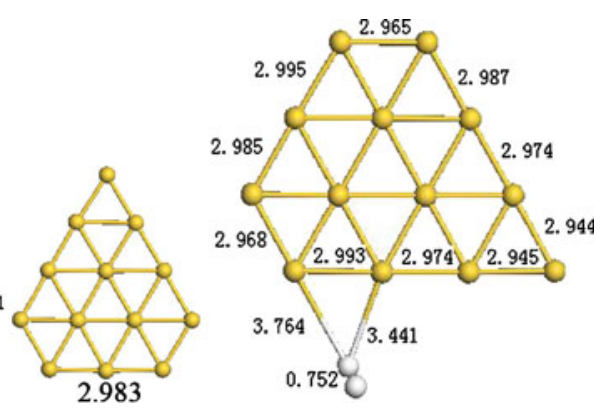

(contd.)

effect might have obvious influence on the adsorption behaviour of small gold cluster toward $\mathrm{H}_{2}$ molecule. It may significantly strengthen the $\mathrm{Au}-\mathrm{H}$ bond and weaken the $\mathrm{H}-\mathrm{H}$ bond, thus, promote the adsorption strength of small gold cluster toward $\mathrm{H}_{2}$ molecule, enhance the dissociation and reactivity of $\mathrm{H}_{2}$ molecule.

\subsection{Energy and electronic structures}

The binding energy $(\mathrm{BE})$, adsorption energy $\left(\mathrm{E}_{\mathrm{ads}}\right)$ and vertical ionization potentials (VIP) for pure $\mathrm{Au}_{n}$ cluster and $\mathrm{Au}_{n} \mathrm{H}_{2}$ cluster are displayed in figures 4-7, where we define:

$$
\begin{aligned}
\mathrm{BE}\left(\mathrm{Au}_{n}\right) & =\left[n \mathrm{E}(\mathrm{Au})-\mathrm{E}\left(\mathrm{Au}_{n}\right)\right] / n \\
\mathrm{BE}\left(\mathrm{Au}_{n} \mathrm{H}_{2}\right) & =\left[n \mathrm{E}(\mathrm{Au})+2 \mathrm{E}(\mathrm{H})-\mathrm{E}\left(\mathrm{Au}_{n} \mathrm{H}_{2}\right)\right] /(n+2) \\
\mathrm{E}_{\mathrm{ads}} & =\left[\mathrm{E}\left(\mathrm{Au}_{n}\right)+\mathrm{E}\left(\mathrm{H}_{2}\right)-\mathrm{E}\left(\mathrm{Au}_{n} \mathrm{H}_{2}\right)\right] \\
\mathrm{VIP} & =\mathrm{E}\left(\mathrm{Au}_{n} \mathrm{H}_{2}\right)^{+}-\mathrm{E}\left(\mathrm{Au}_{n} \mathrm{H}_{2}\right) .
\end{aligned}
$$

Generally speaking, the binding energy of a given cluster is a measurement of its thermodynamic stability. From figure 4, we can find that the binding energy of pure $\mathrm{Au}_{n}$ cluster obtained by AER method is obviously larger than that of pure $\mathrm{Au}_{n}$ cluster obtained

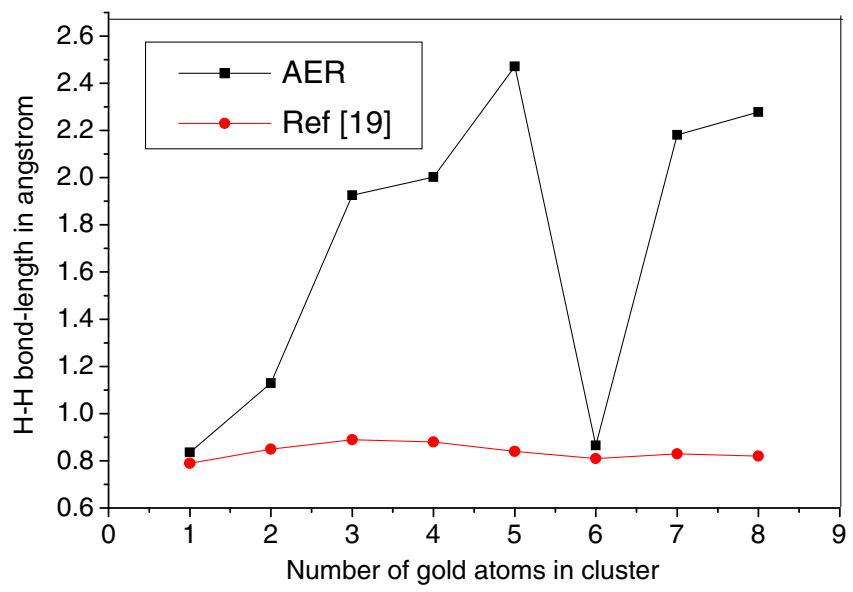

Figure 3. $\mathrm{H}-\mathrm{H}$ bond-length comparison between AER calculation and Ref.19 for $\mathrm{Au}_{n} \mathrm{H}_{2}(n=1-8)$ clusters. 


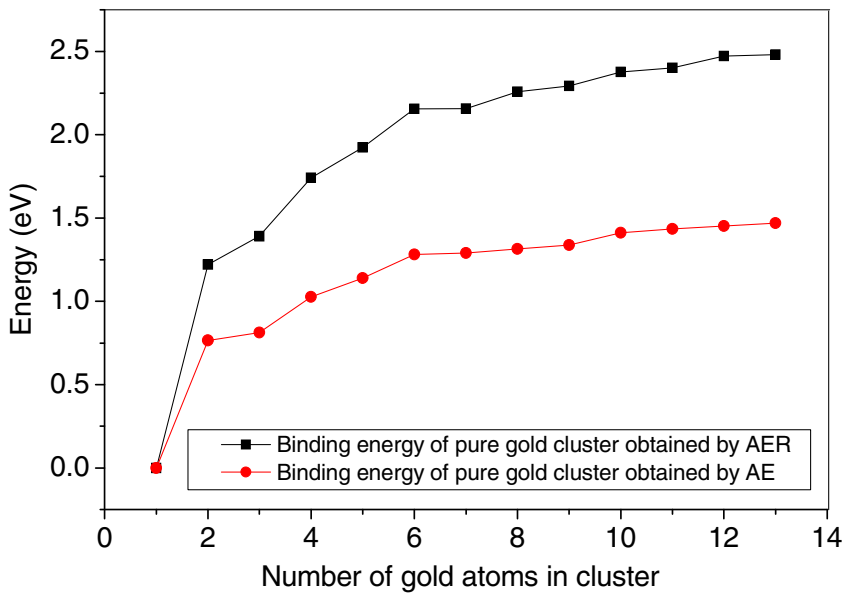

Figure 4. Size dependence of binding energy for pure $\mathrm{Au}_{n}$ cluster.

by $\mathrm{AE}$ method. With increasing size of pure $\mathrm{Au}_{n}$ cluster, the binding energy difference becomes large and then stable gradually, indicating that the scalar relativistic effect enhances the stability of pure $\mathrm{Au}_{n}$ cluster and furthermore this effect is strengthened gradually with increasing size of gold cluster. Similar with pure gold clusters, the binding energy of $\mathrm{Au}_{n} \mathrm{H}_{2}$ cluster obtained by AER method is also obviously larger than that of $\mathrm{Au}_{n} \mathrm{H}_{2}$ cluster obtained by $\mathrm{AE}$ method (see figure 5). With increasing size of $\mathrm{Au}_{n} \mathrm{H}_{2}$ cluster, the binding energies of $\mathrm{Au}_{n} \mathrm{H}_{2}$ clusters obtained by $\mathrm{AE}$ method fluctuate around the value of $1.500 \mathrm{eV}$ and exhibit an odd-even oscillation which can be explained based on the electron pairing effect. ${ }^{54}$ But, the binding energies of $\mathrm{Au}_{n} \mathrm{H}_{2}$ clusters obtained by AER method increase gradually and no obvious odd-even oscillation can be found. The binding energy difference between AER method and AE method becomes larger gradually (see figure 5). All these characteristics infer that the scalar relativistic effect enhances the stability of $\mathrm{Au}_{n} \mathrm{H}_{2}$

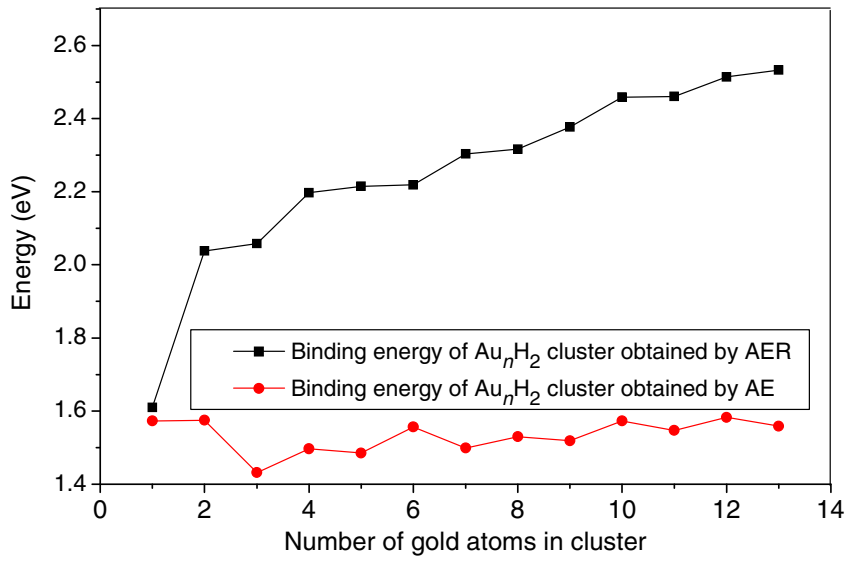

Figure 5. Size dependence of binding energy for $\mathrm{Au}_{n} \mathrm{H}_{2}$ cluster.

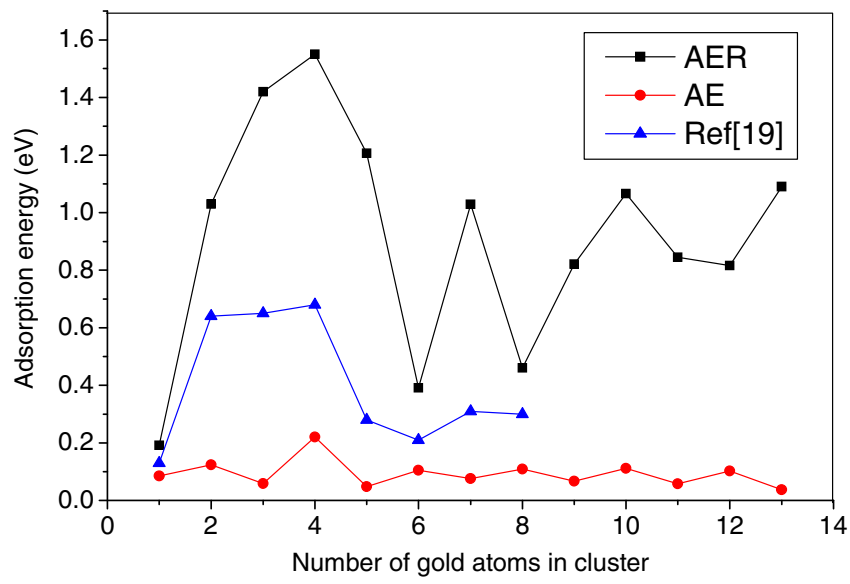

Figure 6. Size dependence of adsorption energy for $\mathrm{Au}_{n} \mathrm{H}_{2}$ cluster.

cluster and with increasing size of $\mathrm{Au}_{n} \mathrm{H}_{2}$ clusters the influence of scalar relativistic effect becomes more and more significant, and conceal the influence of the electron pairing effect gradually.

From the adsorption energies displayed in figure 6, we can see that the adsorption energies of $\mathrm{Au}_{n} \mathrm{H}_{2}$ clusters obtained by $\mathrm{AE}$ method are very small and the adsorption energy of $\mathrm{Au}_{n} \mathrm{H}_{2}$ cluster obtained by AER method is much larger than that of $\mathrm{Au}_{n} \mathrm{H}_{2}$ cluster obtained by AE method. Not only for $\mathrm{Au}_{n} \mathrm{H}_{2}$ cluster obtained by AER method, but also for $\mathrm{Au}_{n} \mathrm{H}_{2}$ cluster obtained by AE method, the adsorption energy reaches the maximum value at $n=4$. Similar with the variation of binding energies, an odd-even oscillation of adsorption energies obtained by AE method can be observed, indicating that the electron pairing effect might play an important role in variation of adsorption energies obtained by $\mathrm{AE}$ method. However, with increasing size of $\mathrm{Au}_{n} \mathrm{H}_{2}$ clusters, the adsorption energies obtained by AER method fluctuate acutely and no obvious odd-even oscillation can be found. In addition, the

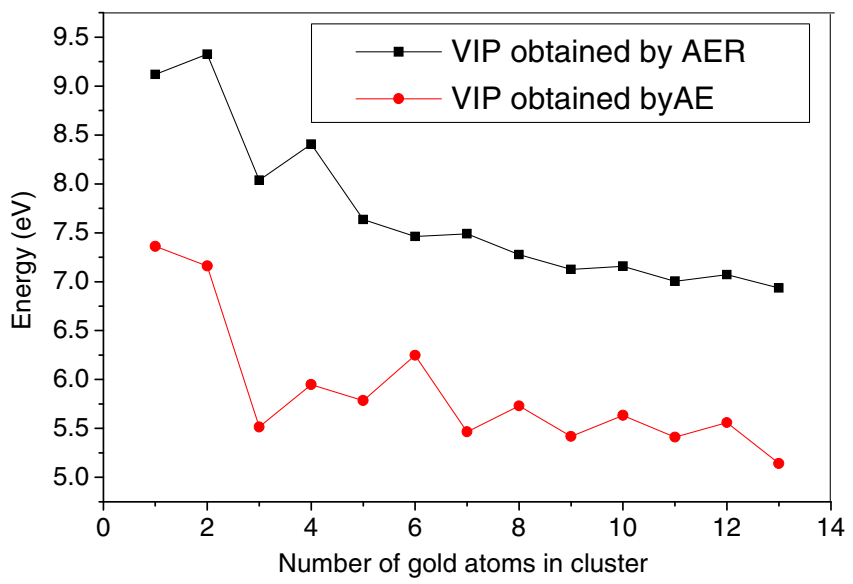

Figure 7. Size dependence of VIP for $\mathrm{Au}_{n} \mathrm{H}_{2}$ cluster. 


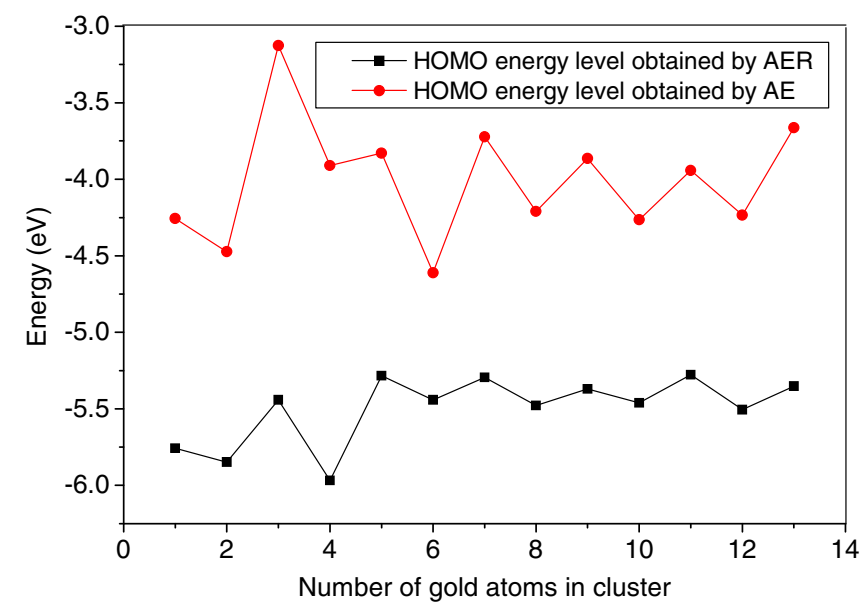

Figure 8. Size dependence of HOMO energy levels for $\mathrm{Au}_{n} \mathrm{H}_{2}$ cluster.

adsorption energy for $\mathrm{Au}_{n} \mathrm{H}_{2}(n=1-8)$ clusters obtained by AER method in our work is larger than the corresponding adsorption energy in previous work ${ }^{19}$ (see figure 6). All these facts suggest that the scalar relativistic effect greatly enhances the adsorption strength of hydrogen molecule onto small gold clusters and plays a more important role than the electron pairing effect. The influence of scalar relativistic effect on the size dependence of adsorption energies is obvious.

The vertical ionization potential (VIP) is often used to investigate the chemical stability of small clusters, the larger of the VIP, the deeper of the HOMO and LUMO energy level, which leads to less reactivity or higher chemical stability. This can be confirmed by $\mathrm{Au}_{n} \mathrm{H}_{2}$ clusters in our work. From figures 7, 8 and 9, we can see that the VIP of $\mathrm{Au}_{n} \mathrm{H}_{2}$ cluster obtained by AER method is larger than that of $\mathrm{Au}_{n} \mathrm{H}_{2}$ cluster obtained by AE method, and the HOMO (LUMO) energy level of $\mathrm{Au}_{n} \mathrm{H}_{2}$ cluster obtained by AER method is deeper than

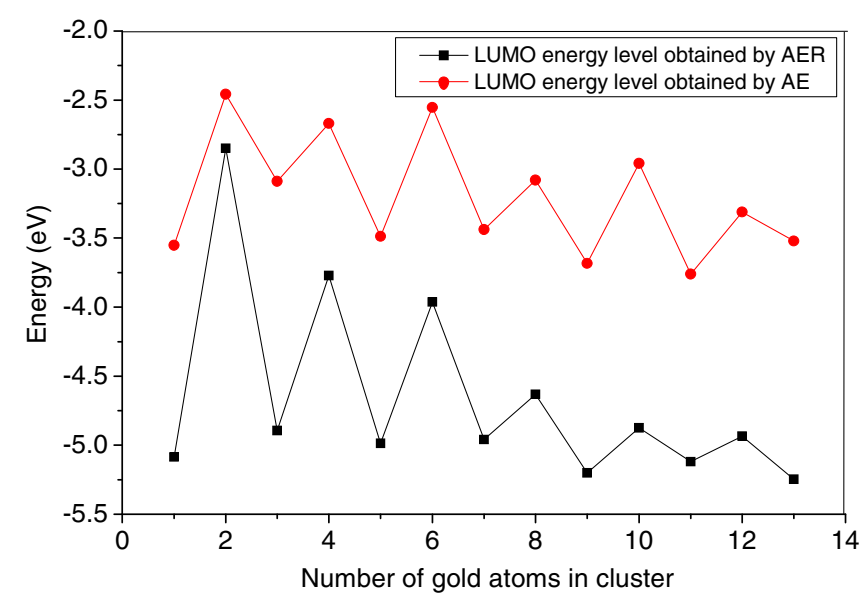

Figure 9. Size dependence of LUMO energy levels for $\mathrm{Au}_{n} \mathrm{H}_{2}$ cluster. that of $\mathrm{Au}_{n} \mathrm{H}_{2}$ cluster obtained by $\mathrm{AE}$ method, indicating that the scalar relativistic effect promotes the chemical stability of $\mathrm{Au}_{n} \mathrm{H}_{2}$ cluster. For all $\mathrm{Au}_{n} \mathrm{H}_{2}$ clusters obtained by AE method, the obvious odd-even oscillations of VIPs and HOMO (LUMO) energy levels can be observed clearly. But, for all $\mathrm{Au}_{n} \mathrm{H}_{2}$ clusters obtained by AER method, only the obvious odd-even oscillation of HOMO (LUMO) energy levels can be seen. The strong scalar relativistic effect in gold lowers the energy of the $6 s$ orbital relative to the $5 d$ orbital $^{55}$ and then has obvious influence on the size dependence of VIPs. However, the odd-even oscillation of HOMO (LUMO) energy levels is mainly the reflection of electron pairing effect and reasonably almost has nothing to do with the scalar relativistic effect.

The interaction between small gold cluster and $\mathrm{H}_{2}$ molecule also can be reflected through charge transfers. We perform a Mulliken charge analysis for $\mathrm{Au}_{n} \mathrm{H}_{2}$ clusters and list the effective charges on $\mathrm{Au}_{n}$ and two $\mathrm{H}$ atoms in table 2. For the lowest energy $\mathrm{Au}_{n} \mathrm{H}_{2}$ clusters obtained by AER, the values of charge transfers suggest a mechanism to favour electron donation, that is, charge transfer from two $\mathrm{H}$ atoms to gold cluster. Some previous works ${ }^{56-58}$ indicated that the charge transfer has the linear correlation with the adsorption energy, the larger charge transfer often leads to the larger adsorption energy, and the variation trend of adsorption energies also can be explained in the light of the charge transfer between gold cluster and $\mathrm{H}_{2}$ molecule. From table 2, we can clearly see that the variation trend of charge transfer between gold cluster and $\mathrm{H}_{2}$ molecule obtained by AER and $\mathrm{AE}$ is in general consistent with the variation trend of adsorption energy obtained by AER and AE, respectively (see figure 6). The largest charge transfer belongs to the $\mathrm{Au}_{4} \mathrm{CO}$ cluster with the largest adsorption energy. However, we must point out that the adsorption energy is also related with the geometries of the cluster, donation and back-donation of electrons, and the overlap of orbital electron cloud. ${ }^{59}$ All these factors might have influence on the adsorption strength. Obviously, the charge transfer from two $\mathrm{H}$ atoms to $\mathrm{Au}_{n}$ obtained by AER is much greater than that obtained by $\mathrm{AE}$, this leads to the larger adsorption energy in $\mathrm{Au}_{n} \mathrm{H}_{2}$ clusters obtained by AER. It is suggested that the scalar relativistic effect might promote the charge transfers from $\mathrm{H}_{2}$ to $\mathrm{Au}_{n}$, strengthen the $\mathrm{Au}-\mathrm{H}$ bond and the adsorption strength of small gold cluster toward $\mathrm{H}_{2}$ and thus give more prominence to the $2 \pi$ molecular orbitals of $\mathrm{H}_{2}$ molecule characterized by the anti-bonding between two $\mathrm{H}$ atoms. In turn, the $\mathrm{H}-\mathrm{H}$ bond is weakened and the reactivity of $\mathrm{H}_{2}$ molecule is enhanced, appearing as the much longer $\mathrm{H}-\mathrm{H}$ distance and dissociation of $\mathrm{H}_{2}$ molecule. 
Table 2. Calculated charge transfer for $\mathrm{Au}_{n} \mathrm{H}_{2}$ clusters.

\begin{tabular}{|c|c|c|c|c|c|c|}
\hline \multirow[b]{3}{*}{ Cluster } & \multicolumn{6}{|c|}{ Charge } \\
\hline & \multicolumn{3}{|c|}{ AER } & \multicolumn{3}{|c|}{$\mathrm{AE}$} \\
\hline & $\mathrm{Au}_{n}$ & $\mathrm{H}$ & $\mathrm{H}$ & $\mathrm{Au}_{n}$ & $\mathrm{H}$ & $\mathrm{H}$ \\
\hline $\mathrm{AuH}_{2}$ & -0.066 & 0.068 & -0.002 & 0.009 & -0.013 & 0.004 \\
\hline $\mathrm{Au}_{2} \mathrm{H}_{2}$ & -0.094 & 0.057 & 0.037 & -0.046 & 0.023 & 0.023 \\
\hline $\mathrm{Au}_{3} \mathrm{H}_{2}$ & -0.108 & 0.054 & 0.054 & -0.004 & 0.002 & 0.002 \\
\hline $\mathrm{Au}_{4} \mathrm{H}_{2}$ & -0.124 & 0.062 & 0.062 & -0.060 & 0.030 & 0.030 \\
\hline $\mathrm{Au}_{5} \mathrm{H}_{2}$ & -0.097 & 0.052 & 0.045 & 0.021 & -0.019 & -0.002 \\
\hline $\mathrm{Au}_{6} \mathrm{H}_{2}$ & -0.078 & 0.044 & 0.034 & 0.022 & -0.021 & -0.001 \\
\hline $\mathrm{Au}_{7} \mathrm{H}_{2}$ & -0.105 & 0.079 & 0.026 & -0.017 & 0.010 & 0.007 \\
\hline $\mathrm{Au}_{8} \mathrm{H}_{2}$ & -0.064 & 0.042 & 0.022 & 0.020 & -0.022 & 0.002 \\
\hline $\mathrm{Au}_{9} \mathrm{H}_{2}$ & -0.079 & 0.048 & 0.031 & -0.016 & 0.012 & 0.004 \\
\hline $\mathrm{Au}_{10} \mathrm{H}_{2}$ & -0.102 & 0.059 & 0.043 & 0.024 & -0.017 & 0.007 \\
\hline $\mathrm{Au}_{11} \mathrm{H}_{2}$ & -0.086 & 0.055 & 0.031 & 0.011 & -0.016 & 0.005 \\
\hline $\mathrm{Au}_{12} \mathrm{H}_{2}$ & -0.080 & 0.049 & 0.031 & 0.021 & -0.019 & 0.002 \\
\hline $\mathrm{Au}_{13} \mathrm{H}_{2}$ & -0.106 & 0.059 & 0.047 & 0.011 & -0.015 & 0.004 \\
\hline
\end{tabular}

From table 3, we can see that all the $\mathrm{Au}_{n} \mathrm{H}_{2}$ clusters obtained by AER and AE method prefer low spin multiplicity $\mathrm{M}\left(\mathrm{M}=1\right.$ for even-numbered $\mathrm{Au}_{n} \mathrm{H}_{2}$ clusters and $\mathrm{M}=2$ for odd-numbered $\mathrm{Au}_{n} \mathrm{H}_{2}$ clusters). The even-numbered $\mathrm{Au}_{n} \mathrm{H}_{2}$ clusters are found to exhibit zero magnetic moment and the odd-numbered $\mathrm{Au}_{n} \mathrm{H}_{2}$ clusters are found to possess magnetic moment with the value of $1 \mu_{B}$ (mainly contributed by $\mathrm{Au}_{n}$ ). The oddeven alteration of magnetic moments for $\mathrm{Au}_{n} \mathrm{H}_{2}$ clusters is very obvious. This situation can be explained in terms of the electron pairing effect. Previous studies ${ }^{59-62}$ have shown that charge transfer and hybridization of valence electrons stemming from host and impurity influence the properties significantly. The stability of the scandium doped gold system is strengthened because of the strong pairing effect between the scandium $3 d$ electrons and gold $6 s$ electrons. It is similar with the situation of the pairing effect between the $6 s$ electrons of $\mathrm{Au}_{n}$ and the $1 s$ electrons of $\mathrm{H}_{2}$ molecule in $\mathrm{Au}_{n} \mathrm{H}_{2}$ clusters of our work. Meanwhile, we can also find that the magnetic moment of $\mathrm{Au}_{n}$ obtained by AER method is obviously larger than that obtained by AE method, this picture of magnetic moments may be understood based on the more chance to be paired of $6 s$ electrons in $\mathrm{Au}_{n}$ and less chance to be paired of $1 s$ electrons in $\mathrm{H}_{2}$ caused by larger charge transfer from $\mathrm{H}_{2}$ to $\mathrm{Au}_{n}$.

In order to understand the nature of chemical bonding in these systems, we have plotted the spatial orientation of the highest occupied molecular orbital (HOMO) and the lowest unoccupied molecular orbital (LUMO) for $\mathrm{Au}_{n} \mathrm{H}_{2}$ clusters obtained by AER and AE method in figure 10. At first glance, the HOMOs and LUMOs of free $\mathrm{H}_{2}$ molecule obtained by AER method and AE method which are characterized by the anti-bonding

Table 3. Calculated magnetic moments for $\mathrm{Au}_{n} \mathrm{H}_{2}$ clusters.

\begin{tabular}{|c|c|c|c|c|c|c|c|c|c|c|}
\hline \multirow[b]{2}{*}{ Cluster } & \multirow[b]{2}{*}{ M } & \multicolumn{4}{|c|}{ Magnetic moment $\left(\mu_{\mathrm{B}}\right)$ AER } & \multirow[b]{2}{*}{ M } & \multicolumn{4}{|c|}{ Magnetic moment $\left(\mu_{\mathrm{B}}\right) \mathrm{AE}$} \\
\hline & & $\mathrm{Au}_{n}$ & $\mathrm{H}$ & $\mathrm{H}$ & Total & & $\mathrm{Au}_{n}$ & $\mathrm{H}$ & $\mathrm{H}$ & Total \\
\hline $\mathrm{AuH}_{2}$ & 2 & 0.918 & -0.032 & 0.114 & 1 & 2 & 0.982 & 0.004 & 0.014 & 1 \\
\hline $\mathrm{Au}_{2} \mathrm{H}_{2}$ & 1 & 0 & 0 & 0 & 0 & 1 & 0 & 0 & 0 & 0 \\
\hline $\mathrm{Au}_{3} \mathrm{H}_{2}$ & 2 & 0.910 & 0.045 & 0.045 & 1 & 2 & 0.998 & 0.001 & 0.001 & 1 \\
\hline $\mathrm{Au}_{4} \mathrm{H}_{2}$ & 1 & 0 & 0 & 0 & 0 & 1 & 0 & 0 & 0 & 0 \\
\hline $\mathrm{Au}_{5} \mathrm{H}_{2}$ & 2 & 0.831 & 0.010 & 0.159 & 1 & 2 & 0.981 & 0.012 & 0.007 & 1 \\
\hline $\mathrm{Au}_{6} \mathrm{H}_{2}$ & 1 & 0 & 0 & 0 & 0 & 1 & 0 & 0 & 0 & 0 \\
\hline $\mathrm{Au}_{7} \mathrm{H}_{2}$ & 2 & 0.902 & 0.003 & 0.095 & 1 & 2 & 0.993 & 0.003 & 0.004 & 1 \\
\hline $\mathrm{Au}_{8} \mathrm{H}_{2}$ & 1 & 0 & 0 & 0 & 0 & 1 & 0 & 0 & 0 & 0 \\
\hline $\mathrm{Au}_{9} \mathrm{H}_{2}$ & 2 & 0.970 & 0.019 & 0.011 & 1 & 2 & 0.996 & 0.002 & 0.002 & 1 \\
\hline $\mathrm{Au}_{10} \mathrm{H}_{2}$ & 1 & 0 & 0 & 0 & 0 & 1 & 0 & 0 & 0 & 0 \\
\hline $\mathrm{Au}_{11} \mathrm{H}_{2}$ & 2 & 0.920 & 0.007 & 0.073 & 1 & 2 & 0.991 & 0.004 & 0.005 & 1 \\
\hline $\mathrm{Au}_{12} \mathrm{H}_{2}$ & 1 & 0 & 0 & 0 & 0 & 1 & 0 & 0 & 0 & 0 \\
\hline $\mathrm{Au}_{13} \mathrm{H}_{2}$ & 2 & 0.950 & 0.040 & 0.010 & 1 & 2 & 0.998 & 0.001 & 0.001 & 1 \\
\hline
\end{tabular}



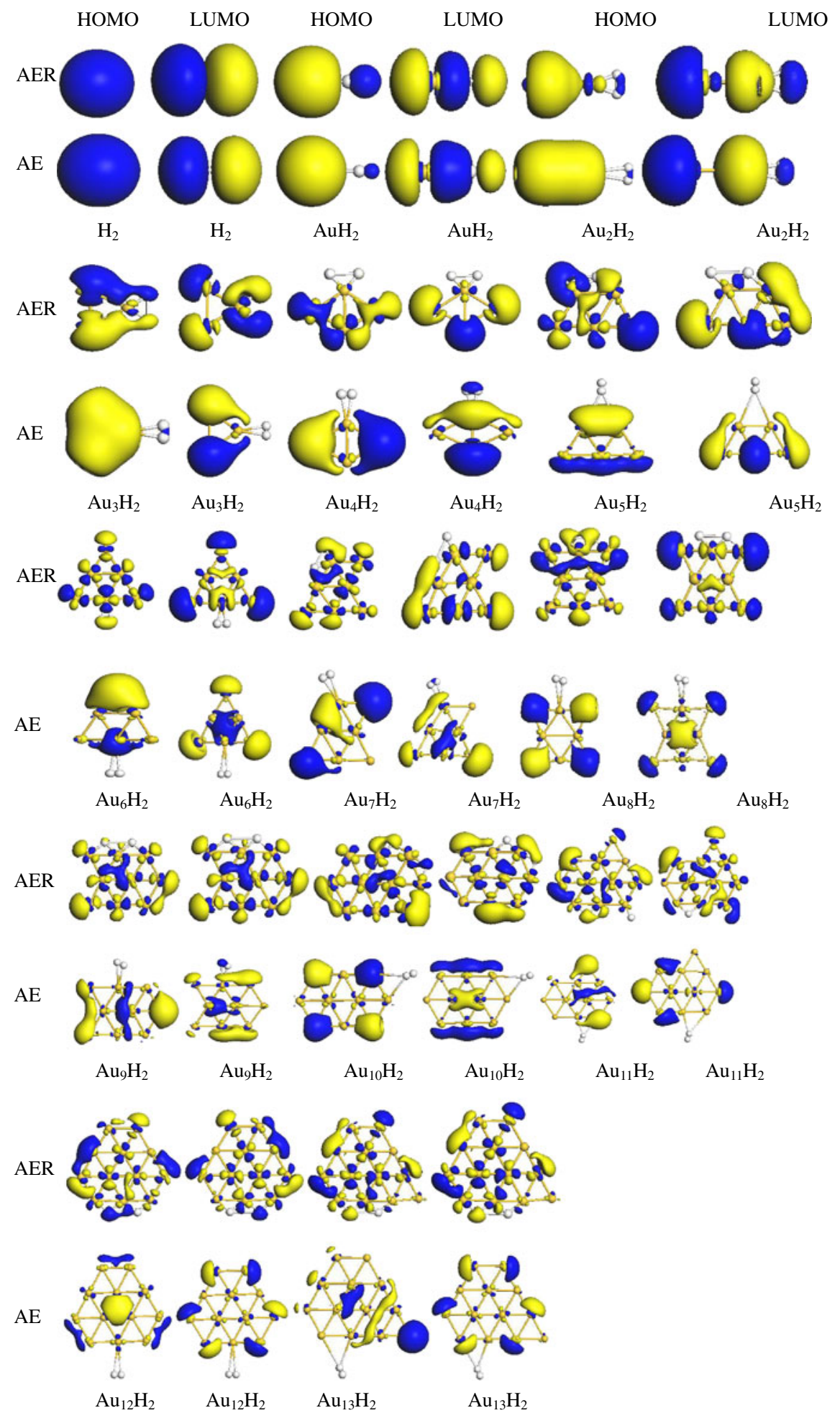

Figure 10. Spatial orientations of HOMO and LUMO for $\mathrm{Au}_{n} \mathrm{H}_{2}(n=1-13)$ clusters.

orbital between two $\mathrm{H}$ atoms are almost same, indicating that the scalar relativistic effect has no influence on the free $\mathrm{H}_{2}$ molecule. It is consistent with the same value of $0.728 \AA$ obtained by AER and AE. For the $\mathrm{Au}_{n} \mathrm{H}_{2}$ clusters obtained by AER, the HOMO and LUMO are delocalized obviously with the con- tribution from almost all atoms in the cluster. With increasing size of $\mathrm{Au}_{n} \mathrm{H}_{2}$ clusters, the delocalization becomes stronger and the distribution of electron cloud is well-mixed and relatively uniform. Besides the strong $s-d$ hybridization in Au atom, the spd hybridization between the $s, d$ orbital of Au atom and the $s$ orbital 
of $\mathrm{H}_{2}$ molecule also exists and is very strong in some $\mathrm{Au}_{n} \mathrm{H}_{2}$ clusters. The electron cloud overlap between the $p \pi *$ orbital of $\mathrm{H}_{2}$ and the $d \sigma+s p$ hybridized orbital of $\mathrm{Au}$ for some $\mathrm{Au}_{n} \mathrm{H}_{2}$ clusters is also illustrated. But, the electron cloud overlap between the frontier orbital of two $\mathrm{H}$ atoms can not be found in most $\mathrm{Au}_{n} \mathrm{H}_{2}$ clusters. On the contrary, the obvious delocalization of HOMOs and LUMOs only can be found in some small $\mathrm{Au}_{n} \mathrm{H}_{2}$ clusters obtained by AE method. With increasing size of $\mathrm{Au}_{n} \mathrm{H}_{2}$ clusters, the HOMO and LUMO have become more and more localized with the contribution from only a few atoms in the cluster. This discrepancy may be explained in terms of the strong scalar relativistic effect in small gold cluster. The strong scalar relativistic effect caused by the high speed motion of out shell electrons and the spin-orbit coupling leads to the shrinking of the size of the $s$ orbitals, lowers the corresponding energy level and enhances the shielding effect of inner electrons. Thus, promotes the outward expanding of the $d, f$ orbitals and makes the $s, d$ electrons closer. The enhancement of $s-d$ hybridization is very obvious and the frontier orbitals become dispersive. The total energy of system decreases and the stability enhancement may be expected. Meanwhile, $\mathrm{H}_{2}$ molecule adsorption onto a gold cluster can be seen that it is only partly involving an excitation of the formerly unoccupied orbital in the cluster, since the open shell has to be 'pushed up' when the cluster-H bond is formed. The same argument can also be found in connection with the bond preparation method used in the cluster surface model ${ }^{63}$ and is also the reason why the $\mathrm{H}$ orbitals can not be seen in many HOMOs and LUMOs of $\mathrm{Au}_{n} \mathrm{H}_{2}$ clusters.

\subsection{Frequency analysis}

Since many experiments on the adsorption behaviour of nanosized gold clusters were based on the FTIR method and focused on the vibrational frequency of different mode in the adsorption system. Higher vibrational frequency often corresponds to the stronger interaction between the specified bonded atoms. From table 4 , it is easy to be found that the highest frequency of $\mathrm{Au}-\mathrm{H}$ mode obtained by AER method is significantly higher than that of $\mathrm{Au}-\mathrm{H}$ mode obtained by $\mathrm{AE}$ method and the highest frequency of $\mathrm{H}-\mathrm{H}$ mode obtained by AER method is obviously lower than that of $\mathrm{H}-\mathrm{H}$ mode obtained by AE method. Meanwhile, all the highest vibrational frequencies of $\mathrm{H}-\mathrm{H}$ mode obtained by AER and AE methods are lower than those of single $\mathrm{H}_{2}$ molecule. It is believed that after adsorption, the $\mathrm{H}-\mathrm{H}$ interaction is weakened and reactivity of $\mathrm{H}_{2}$ is enhanced for all $\mathrm{Au}_{n} \mathrm{H}_{2}$ clusters obtained by AER and $\mathrm{AE}$ method. The scalar relativistic effect might
Table 4. The calculated highest frequencies of $\mathrm{Au}-\mathrm{Au}$, $\mathrm{Au}-\mathrm{H}$ and $\mathrm{H}-\mathrm{H}$ mode for $\mathrm{Au}_{n} \mathrm{H}_{2}$ clusters.

\begin{tabular}{llllll}
\hline & \multicolumn{2}{c}{$v_{A u-H}\left(\mathrm{~cm}^{-1}\right)$} & & \multicolumn{2}{c}{$v_{H-H}\left(\mathrm{~cm}^{-1}\right)$} \\
\cline { 2 - 3 } \cline { 5 - 6 } Cluster & AER & AE & & AER & AE \\
\hline $\mathrm{H}_{2}$ & & & & 4387.2 & 4392.7 \\
$\mathrm{AuH}_{2}$ & 336.8 & 179.1 & & 3656.5 & 4274.3 \\
$\mathrm{Au}_{2} \mathrm{H}_{2}$ & 304.9 & 180.8 & & 2447.0 & 4314.3 \\
$\mathrm{Au}_{3} \mathrm{H}_{2}$ & 485.7 & 108.4 & & 2368.4 & 4360.2 \\
$\mathrm{Au}_{4} \mathrm{H}_{2}$ & 443.4 & 119.3 & & 2313.0 & 3986.1 \\
$\mathrm{Au}_{5} \mathrm{H}_{2}$ & 417.5 & 124.5 & & 2202.0 & 4317.0 \\
$\mathrm{Au}_{6} \mathrm{H}_{2}$ & 272.6 & 128.2 & & 3052.8 & 4351.3 \\
$\mathrm{Au}_{7} \mathrm{H}_{2}$ & 416.0 & 130.8 & & 2081.1 & 4281.3 \\
$\mathrm{Au}_{8} \mathrm{H}_{2}$ & 401.9 & 137.6 & & 1615.8 & 4301.7 \\
$\mathrm{Au}_{9} \mathrm{H}_{2}$ & 378.2 & 174.4 & & 1481.4 & 4187.5 \\
$\mathrm{Au}_{10} \mathrm{H}_{2}$ & 315.5 & 144.4 & & 1475.7 & 4315.3 \\
$\mathrm{Au}_{11} \mathrm{H}_{2}$ & 397.6 & 143.6 & & 1419.1 & 4281.7 \\
$\mathrm{Au}_{12} \mathrm{H}_{2}$ & 391.0 & 127.0 & & 1432.6 & 4356.7 \\
$\mathrm{Au}_{13} \mathrm{H}_{2}$ & 380.8 & 123.8 & & 1439.2 & 4329.4 \\
\hline
\end{tabular}

strengthen the $\mathrm{Au}-\mathrm{H}$ interaction and weaken the $\mathrm{H}-\mathrm{H}$ interaction, appearing as the much shorter $\mathrm{Au}-\mathrm{H}$ bondlength and much longer $\mathrm{H}-\mathrm{H}$ distance. It also proves again that the scalar relativistic effect is favourable to the dissociative adsorption of $\mathrm{H}_{2}$ molecule onto small gold cluster and the reactivity enhancement of $\mathrm{H}_{2}$ molecule.

\section{Conclusions}

In this paper, a comparative study between all-electron relativistic (AER) calculation and all-electron (AE) calculation on the $\mathrm{H}_{2}$ molecule adsorption onto small gold clusters has been made. Compared with the corresponding $\mathrm{Au}_{n} \mathrm{H}_{2}$ cluster obtained by $\mathrm{AE}$ method, the $\mathrm{Au}_{n} \mathrm{H}_{2}$ cluster obtained by AER method has much shorter $\mathrm{Au}-$ $\mathrm{H}$ bond-length, much longer $\mathrm{H}-\mathrm{H}$ distance, larger binding energy and adsorption energy, higher VIP, greater charge transfer, higher vibrational frequency of $\mathrm{Au}-\mathrm{H}$ mode and lower vibrational frequency of $\mathrm{H}-\mathrm{H}$ mode. All these characteristics suggest that the scalar relativistic effect might strengthen the $\mathrm{Au}-\mathrm{H}$ bond and weaken the $\mathrm{H}-\mathrm{H}$ bond, appearing as the much shorter $\mathrm{Au}-\mathrm{H}$ bond-length and much longer $\mathrm{H}-\mathrm{H}$ distance. The delocalization of HOMO and LUMO for $\mathrm{Au}_{n} \mathrm{H}_{2}$ cluster obtained by AER method is obvious. It is believed that the scalar relativistic effect is favourable to the $\mathrm{H}_{2}$ molecule adsorption onto small gold cluster and the reactivity enhancement of $\mathrm{H}_{2}$ molecule. It is also one of the reasons why the dissociative adsorptions take place in some $\mathrm{Au}_{n} \mathrm{H}_{2}$ clusters. With increasing size of $\mathrm{Au}_{n} \mathrm{H}_{2}$ clusters, the influence of scalar relativistic effect becomes more significant. Some further studies 
focused on the influence of scalar relativistic effect on the adsorption behaviour of other small molecules onto gold clusters are necessary in the future.

\section{Acknowledgements}

This work was supported by the Doctoral Foundation of Southwest University of Science and Technology, China (No. 12zx701).

\section{References}

1. Wang Y and Gong X G 2006 J. Chem. Phys. 125124703

2. Schmid G 1992 Chem. Rev. 921709

3. Alivisatos A P 1996 Science 271933

4. Valden M, Lai X and Goodman D W 1998 Science 281 1647

5. Meier D C and Goodman D W 2004 J. Am. Chem. Soc. 1261892

6. Haruta M, Tsubota S, Kobayashi T, Kageyama H, Genet M J and Delmon B 1993 J. Catal. 144175

7. Okumura M, Coronado J M, Soria J, Haruta $\mathrm{M}$ and Conesa J C 2001 J. Catal. 203168

8. Boccuzzi F, Chiorino A, Manzoli M and Haruta M 2001 J. Catal. 202256

9. Mul G, Zwijnenburg A, Linden B V, Makkee M and Moulijn J A 2001 J. Catal. 201128

10. Jia J F, Haraki K, Kondo J N, Domen K and Tamaru K 2000 J. Phys. Chem. B 10411153

11. Sárkány A and Révay Z 2003 Appl. Catal. A: Gen. 243 347

12. Bond D C and Thompson D T 1999 Catal. Rev. Sci. Eng. 41319

13. Hutchins G J 2002 Catal Today 7211

14. Boyd G C 2002 Catal Today 725

15. Haruta M 1997 Catal Today 36153

16. Haruta M and Date M 2001 Appl. Catal. A: Gen 222427

17. Varganov S A, Olson R M, Gordon M S, Mills G and Metiu H 2004 J. Chem. Phys. 1205169

18. Okumura M, Kitagawa $Y$, Haruta $M$ and Yamaguchi $Y$ 2005 Appl. Catal. A: Gen. 29137

19. Ghebriel H W and Kshirsagar A 2007 J. Chem. Phys. 126244705

20. Kang G J, Chen Z X, Li Z and He X 2009 J. Chem. Phys. 130034701

21. Wang Y and Gong X G 2006 J. Chem. Phys. 125124703

22. Sugawara K, Sobott F and Vajhtin A B 2003 J. Chem. Phys. 1187808

23. Cox D M, Brickman R O, Greegan K and Kaldor A 1991 Z. Phys. D: At. Mol. Clusters. 19353

24. Cox D M, Brickman R O, Greegan K and Kaldor A 1991 Mater. Res. Soc. Symp. Proc. 20643

25. Corma A, Boronat M, González S and Illas F 2007 Chem. Commun. 1253371

26. Strømsnes H, Jusuf S, Schimmelpfennig B, Wahlgren U and Gropen O 2001 J. Mol. Struct. 567137

27. Barrio L, Liu P, Rodríguez J A, Campos-Martín J M and Fierro J L 2006 J. Chem. Phys. 125164715

28. Claus P 2005 Appl. Catal. A: Gen. 291222

29. Panayotov D A and Yates J T 2007 J. Phys. Chem. C 111 2959
30. Datta S N, Ewig C S and VanWazer J R 1978 Chem. Phys. Lett. 5783

31. Lee Y S, Ermler W C and Pitzer K S 1997 J. Chem. Phys 675861

32. Jain P K 2005 Struct. Chem. 16421

33. Gilb S, Weis P, Furche F, Ahlrichs P and Kappes M 2002 J. Chem. Phys. 1164094

34. Häkkinen H, Moseler M and Landman U 2002 Phys. Rev. Lett. 89033401

35. Fernandez E M, Soler J M, Garzon L L and Balbas C 2004 Phys. Rev. B 70165403

36. Wesendrup R, Hunt $\mathrm{T}$ and Schwerdtfeger P $2000 \mathrm{~J}$. Chem. Phys. 1129356

37. Autschbach J, Siekierski S, Seth M, Schwerdtfeger P and Schwarz W H E 2002 J. Сотри. Chem. 23 804

38. Delley B 1990 J. Chem. Phys. 92508

39. Delley B 2000 J. Chem. Phys. 1137756

40. Perdew J P and Wang Y 1992 Phys. Rev. B 4513244

41. Delley B 2002 Phys. Rev. B 66155125

42. Belpassi L, Tarantelli F, Sgamellotti A and Quiney H M 2008 Phys. Rev. B 77233403

43. Assadollahzadeh B and Schwerdtfeger P 2009 J. Chem. Phys. 131064306

44. Deka A and Deka R C 2008 J. Mol. Struct: (Theochem). 87083

45. Mao H P, Wang H Y, Ni Y and Xu G L 2004 Acta. Phys. Sinica. $\mathbf{5 3} 1766$

46. Huber K P and Herzberg G 1979 Constants of diatomic molecules (New York: Van Nostrand Reinhold)

47. Jackschath C, Rabin I, Schulze W and Bunsenges B 1992 Phys. Chem. 961200

48. Hakkinen H, Yoon B, Landman U, Li X, Zhai H J and Wang L S 2003 J. Phys. Chem. A 1076168

49. Kuang X J, Wang X Q and Liu G B 2010 Catal. Lett. 137(3-4) 247

50. Kuang X J, Wang X Q and Liu G B 2011 Eur. Phys. J. $D$ 61(1) 71

51. Kuang X J, Wang X Q and Liu G B 2011 Appl. Surface Sci. 257(15) 6546

52. Kuang X J, Wang X Q and Liu G B 2010 Phys. B: Phys. Condensed Matter. 405(16) 3328

53. Lide D R 2001 Handbook of chemistry and physics, 2nd ed. (Boca Raton: CRC Press) 9

54. Phala S, Klatt G and Steen E V 2004 Chem. Phys. Lett. 39533

55. Pyykko P 1988 Chem. Rev. 88563

56. Ge G X, Yang Z Q and Cao H B 2009 Acta. Phys. Sin. 586128

57. Ge G X, Cao H B, Jing Q and Luo Y H 2009 Acta. Phys. Sin. $\mathbf{5 8} 8236$

58. Sun L S, Zhang A C, Xiang J, Guo P H, Liu Z C and Su S 2011 Acta. Phys. Sin. 60073103

59. Joshi A M, Delgass W N and Thomson K T $2006 \mathrm{~J}$. Phys. Chem. B110 23373

60. Torres M B, Fernández E M and Balbás L C 2006 Phys. Rev. B71 155412

61. Majumder C, Kandalam A K and Jena P 2006 Phys. Rev. B74 205437

62. Janssens E, Tanaka H, Neukermans S, Silverans R E and Lievens P 2004 Phys. Rev. B69 085402

63. Panas L, Siegbahn P and Walhgren U 1987 Chem. Phys. 112325 